\title{
Organic acids and/or compound with defined microorganisms to control Salmonella enterica serovar Enteritidis experimental infection in chickens
}

- Author(s)
Sterzo EV
Paiva JB
Mesquita AL
Freitas Neto OC
Berchieri Jr A
Department of Animal Pathology of Faculdade
de Ciência Agrárias e Veterinárias de
Jaboticabal (FCAV-Unesp).

Mail Address

Angelo Berchieri Junior

FCAV-Unesp

Via de acesso Paulo Donato Castellane, s/n,

14.884-900. Jaboticabal, SP, Brazil.

Email: berchier@fcav.unesp.br

\section{Keywords}

Competitive exclusion; organic acids; probiotic; Salmonella Enteritidis.

\section{Acknowledgements}

We would like to thank FAPESP and CNPq for their financial support, and A.J. dos Santos and A.R. Baptista for their technical help.
Arrived: October / 2006

Approved: February / 2007

\section{ABSTRACT}

The association of human foodborne salmonellosis with poultry products enhanced the efforts to control Salmonella Enteritidis in poultry farms. Dietary organic acid supplementation is one of the measures currently used to reduce the presence of undesirable microorganisms. Another method to control enteric Salmonella in poultry is competitive exclusion using defined or undefined microorganisms products. Organic acids and microbiological methods to accelerate the development of the intestinal microbiota can be used individually or in combination. The present study evaluated the effect of dietary supplementation of an acidifier and of a defined multi-strain microbial mixture (Biomin ${ }^{\circledR}$ PoultryStar) via drinking water in the control of the intestinal colonization of broilers by Salmonella Enteritidis. Four experiments were performed. The first experiment showed that the organic acids mixture was able to prevent Salmonella Enteritidis colonization of ceca in both inclusion rates applied $(p<0.05)$. In the second and third experiments the probiotic either individually or in combination the acidifier, both in high and low doses reduced the incidence of Salmonella Enteritidis in the cecal contents $(p<0.05)$. In these three experiments, birds were orally challenged. Similar results were obtained in a fourth trial, in which challenge was made by contact.

\section{INTRODUCTION}

The control of Salmonella in commercial poultry was necessary for the development of poultry industry. Rearing birds in high densities, living in close contact with feces allows the infection and the dissemination of pathogens. Therefore, pathogenic bacteria associated to human foodborne diseases must be controlled. In the beginning of the 1980s worldwide outbreaks of human salmonellosis caused by Salmonella Enteritidis were linked to the consumption of poultry products, leading to a reinforcement of measures to control Salmonella in broilers (Wray \& Davies, 1994), which started in Brazil around 1990 and was responsible for a plan to control avian diseases in the Brazilian poultry industry (PNSA) (Brasil, 2003).

One of the control measures was the inclusion of organic acids into the feed, aiming at reducing the number of undesirable microorganisms. Organic acids inhibit bacterial growth by decreasing intestinal $\mathrm{pH}$ (Barcellos et al., 2004), interfere with bacterial metabolism by decreasing the cytoplasmatic $\mathrm{pH}$, as well as inhibit enzymatic action and DNA synthesis (Vieira \& Viola, 2004). However, organic acid compounds do not cause residues in meat, and therefore are not harmful to human beings. The mode of action of organic acids on infectious pathogenic microorganisms was well documented by Cherrington et al. (1991). A blend of formic acid and propionic acid included in the feed can prevent 
cecal colonization of newly-hatched chicks by Salmonella enterica serovars Typhimurium, Enteritidis, Agona and Infantis (Iba \& Berchieri Jr., 1995). This is consistent with previous findings by Hinton \& Linton (1988), who reported that a blend of organic acids did not completely eliminate Salmonella from treated feed, but when this feed was given to the birds, there was no cecal colonization by Salmonella. According to Cherrington et al. (1991), the full action of organic acids is expressed in the crop due to its high moistures content humidity. However, according to Oliveira et al. (2000), the contamination by contact between infected and non-infected birds cannot be controlled by organic acids.

Another way to control enteric Salmonella in poultry is competitive exclusion, using defined or undefined microorganisms mixtures. This procedure was described initially by Nurmi \& Rantala (1973), and was later supported by several studies conducted worldwide (Ziprin et al., 1993; Mead, 2000; Schneitz, 2005). Undefined cultures usually showed better performance as compared to products containing a defined culture of microorganisms (Hinton \& Mead, 1991). The competitive exclusion effect is apparently due to the competition for sites of adherence, and to a decrease in cecal $\mathrm{pH}$ through the production of short chain volatile organic acids (Ziprin et al., 1991). Although a defined culture of microorganisms is indicated to prevent enteric colonization by Salmonella, this method is controversial. The bacteria present in the culture can improve the composition of the intestinal flora (Santos \& Turnes, 2005), by improving the quality of the intestinal villi (Luqueti et al, 2005). This may allow the control of enteric pathogenic bacteria without the use of the antimicrobial drugs (Santos \& Turnes, 2005).

One of the main sources of Salmonella infections in poultry farms is the feed. For this reason, efforts have been made to improve the microbiological quality of feed by adding organic acids to the feed, and by offering competitive exclusion products to the newlyhatched chicks in order to accelerate of the establishment of the microflora. These two classes of products can be used together, with no influence on each other, as demonstrated by Hinton et al. (1991) and Oliveira et al. (2000).

This study aimed at evaluating the effect of a commercial blend of organic acids (acidifier) and a welldefined multi-strain probiotic product, containing microorganisms to colonize the gut of day-old chicks in the intestinal colonization by Salmonella. The acidifier contained formic acid and propionic acid. The defined microbial product included following probiotic strains: Enterococcus sp., Pediococcus sp., Bifidobacterium sp. and Lactobacillus spp, which were isolated from different parts of the gastrointestinal tract of broilers and selected for their ability to establish a healthy gut.

\section{MATERIAL AND METHODS}

\section{a) Bacterium challenge}

A spontaneous mutant of the Salmonella enterica serovar Enteritidis, resistant to nalidixic acid and spectinomycin (SE Nal'SpCr), kept by the laboratory of avian diseases of the FCAV-Unesp, was used. Broth culture was prepared in nutrient broth (Oxoid CM 67) incubated at $37^{\circ} \mathrm{C}$ for 18 hours in a shaking incubator. The culture contained between 1.3 and $3.3 \times 10^{9} \mathrm{CFU} /$ $\mathrm{mL}$.

This overnight broth culture of SE Nal'Spec' was diluted 1000 times in fresh nutrient broth. Birds were challenged either by inoculating $0.1 \mathrm{~mL}$ directly inoculated into the crop of 3-day-old chicks, or by contact, placing two infected birds in each box, which housed 9 uninfected birds.

\section{b) Inclusion of acidifier into feed}

The acidifier was included at $1.5 \mathrm{~kg}$ per ton or $3.0 \mathrm{~kg}$ per ton of feed.

\section{c) Inclusion of defined probiotic product}

During the first three days of the chicks' life, the multi-strain probiotic (Biomin ${ }^{\circledR}$ PoultryStar, Biomin $\mathrm{GmbH}$, Austria) was daily added to the drinking water at a concentration of $20 \mathrm{~g}$ per 1,000 birds.

\section{d) Birds}

Day-old broiler chicks were provided by a commercial hatchery. At arrival, chicks they were inspected to ensure they were free from Salmonella. Drag swabs were taken from inside the transport boxes, and blood from several birds for serological examination. Swabs were placed in a flask containing Selenite broth (Oxoid CM 395 + L121) plus novobiocin, and incubated at $37^{\circ} \mathrm{C}$ overnight before plating on brilliant green agar, and then again incubated at $37^{\circ} \mathrm{C}$ overnight (Zancan et al., 2000; Gama et al., 2003). Serum samples were tested by slide agglutination test with Salmonella colonies grown on nutrient agar.

Birds were placed in netted wooden boxes, which were previously disinfected. Boxes were equipped with a heating source, water and commercial starter feed 
with no antimicrobial drugs were offered ad libitum. There were nine birds per box, with two boxes per experimental group. When birds were challenged by contact, two additional seeder birds (experiment 4) were placed in each pen.

\section{e) Bacterial enumeration}

The method of bacterium enumeration was performed according to Barrow et al. (1987). Decimal dilutions of the cecal contents were prepared using PBS pH 7.4 (saline buffer), and bacteria were counted on brilliant green agar plates (Oxoid CM 263), containing sodium nalidixate $(100 \mathrm{mg} / \mathrm{mL})$ and spectinomycin $(100 \mathrm{mg} / \mathrm{mL})$. The plates were incubated at $37^{\circ} \mathrm{C}$ for 24 hours. The results (CFU/g) were transformed in $\log _{10}$, and submitted to analysis of variance. Means were compared by the test of Tukey $(p<0.05$; SAS, 2002).

\section{f) Experimental design}

Four experiments were performed. Nine birds per replicate, 2 replicates per group.

\section{Experiment 1}

Two batches of feed were treated with acidifier, one containing $1.5 \mathrm{~kg}$ per ton of feed (group A), and the other $3.0 \mathrm{~kg}$ per ton (group B). A third batch did not include any organic acids blend (group C).

Birds were challenged via inoculation into the crop at thre days of age. At 5, 7, and 10 days of age three birds were sacrificed, and their cecal contents were examined to estimate viable SE Nal'Spcr counts.

\section{Experiment 2}

This experiment included four groups:

Group A - feed containing $3.0 \mathrm{~kg}$ acidifier per ton of feed

Group B - feed containing $3.0 \mathrm{~kg}$ acidifier per ton of feed, and probiotic added to the drinking water

Group C - drinking water with probiotic

Group D - no additives

SE Nal'Spcr challenge and counting were carried out as described in experiment 1.

\section{Experiment 3}

This experiment included three groups:

Group A - drinking water with probiotic

Group B - feed containing $1.5 \mathrm{~kg}$ acidifier per ton of feed, and probiotic added to the drinking water

Group C - no additives

SE Nal'Spc challenge and counting were carried out as described in experiment 1 .

\section{Experiment 4}

This experiment was carried out as experiment 3, but instead of individually inoculating birds, two infected birds were placed inside each box on the third day of life of the newly-hatched chicks.

\section{RESULTS}

The inspection of the birds and the transport boxes at arrival did not show any evidence of Salmonella sp.

The first experiment was carried out to assess the effect of two concentrations of the feed acidifier on the prevention of cecal colonization by SE Nal'Spcr. As shown in Table 1, both inclusion rates used were able to reduce viable SE Nal'Spcr counts; however, the best results were obtained when the feed contained $3.0 \mathrm{~kg}$ of the product per ton $(p<0.05)$.

In the second experiment (Table 2), the effect of the feed acidifier ( $3 \mathrm{~kg} / \mathrm{ton}$ of feed) and the probiotic added to the drinking water was simultaneously evaluated. The results showed that either the acidifier or probiotic alone, or both products together prevented the cecal colonization by SE Nal'Spcr $(p<.05)$.

The third experiment (Table 3) was performed to assess the effect of the defined multi-strain probiotic product alone, and of a combination of the acidifier at a lower inclusion rate $(1.5 \mathrm{~kg} /$ ton $)$ and the probiotic . The results indicated that all treatments prevented cecal colonization by SE Nal'Spcr $(p<0.05)$.

Due to the interesting results obtained in the previous three experiments with individually infected birds, a fourth trial was carried out to check if the same results could be obtained if contact the infection was promoted by the contact of infected with non-infected birds. The results in Table 4 show that there was a decrease in cecal colonization by SE Nal'Spcr with the combination of products, but the best results were obtained when the defined multi-strain probiotic product was used alone.

\section{DISCUSSION}

The association of poultry salmonellosis to human foodborne disease put pressure on the efforts to control Salmonella Enteritidis in poultry farms. The use of 


\begin{tabular}{|c|c|c|}
\hline Group & Treatment & $\log _{10}$ viable number of SE Nal/Spec per gram of cecal contents \\
\hline A & ACIDIFIER (1.5 Kg/ton) & $4.59 \#(2.75-6.33) a b^{*}$ \\
\hline B & ACIDIFIER (3.0 Kg/ton) & $3.47(\mathrm{~N}-5.25) a$ \\
\hline C & No additive (Control) & $5.06(3.45-6.67) b$ \\
\hline \multicolumn{3}{|c|}{$\begin{array}{l}\text { \# Viable counts are expressed as mean from } 18 \text { birds (range in parenthesis). } N=\log _{10}<2 .{ }^{*} \text { Means followed by different letters are significantly } \\
\text { different (Tukey, } p<0.05 \text { ). }\end{array}$} \\
\hline Group & Treatment & $\log _{10}$ viable number of SE Nal/Spec per gram of cecal contents \\
\hline A & ACIDIFIER (3.0 kg/ton) & $2.43 \#(N-3.68) a^{*}$ \\
\hline B & ACIDIFIER (3.0 kg/ton)Biomin ${ }^{\sqrt{B}}$ PoultryStar (20 g/1000 birds) & $\mathrm{N}(\mathrm{N}-\mathrm{N}) \mathrm{a}$ \\
\hline C & Biomin PoultryStar (20g/1000 birds) & $\mathrm{N}(\mathrm{N}-\mathrm{N})$ a \\
\hline D & No feed additive (Control) & $3.62(N-5.53) b$ \\
\hline
\end{tabular}

\# Viable counts are expressed as mean from 18 birds (range in parenthesis). $\mathrm{N}=\log _{10}<2$. ${ }^{*}$ Means followed by different letters are significantly different (Tukey, $p<0.05)$.

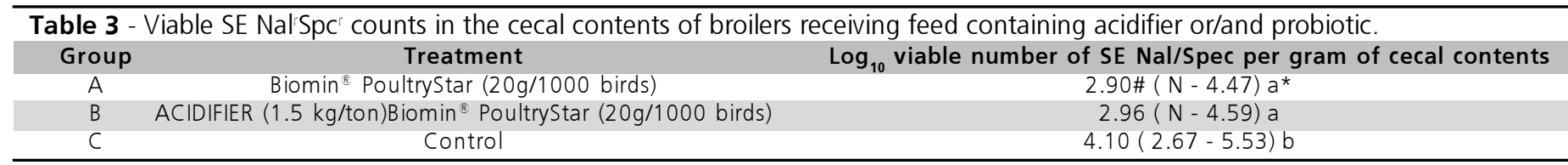

\# Viable counts are expressed as mean from 18 birds (range in parenthesis). $\mathrm{N}=\log _{10}<2 .{ }^{*}$ Means followed by different letters are significantly different (Tukey, $p<0.05$ ).

\begin{tabular}{|c|c|c|}
\hline Grupo & Treatment & $\log _{10}$ viable number of SE Nal/Spec per gram of cecal contents \\
\hline A & Biomin ${ }^{\circledR}$ PoultryStar (20g/1000 birds) & $2,75 \#(N-3,87) a^{*}$ \\
\hline B & ACIDIFIER (1.5 kg/ton) Biomin ${ }^{\mathbb{P}}$ PoultryStar $(20 \mathrm{~g} / 1000 \mathrm{birds})$ & $3,48(N-5,26) a b$ \\
\hline C & Control & $4,01(2,67-5,68) b$ \\
\hline
\end{tabular}

\# Viable counts are expressed as mean from 18 birds (range in parenthesis). $\mathrm{N}=\log _{10}<2 .{ }^{*}$ Means followed by different letters are significantly different (Tukey, $p<0.05$ ).

organic acids and microbiological methods, alone or together, to accelerate the development of the intestinal microbiota has been suggested (Hinton et al., 1991; Oliveira et al., 2000). Therefore, the present study aimed at assessing the effects of the feed inclusion of an acidifier and the administration of a defined multistrain microbial product (Biomin ${ }^{\circledR}$ PoultryStar) via drinking water on the control of the intestinal colonization by Salmonella Enteritidis in broilers.

According to the data shown in Table 1, the acidifier was able to prevent cecal colonization by Salmonella Enteritidis in both applied inclusion rates $(p<0.05)$, but the best better results were obtained when at the higher inclusion rate.

Based on these results, a second experiment was performed, now also including the acidifier at a higher inclusion rate ( $3 \mathrm{~kg} / \mathrm{ton})$. The results exhibited in Table 2 show that the probiotic product either alone, or with the acidifier, was able to reduce the presence of Salmonella Enteritidis in the cecal contents. Although the products assessed here are not the same as used in previous investigations, the results are consistent with those of previous studies, in which organic acid compounds did not interfere with the action of products for the establishment of the intestinal microbiota (Hinton et al., 1991; Oliveira et al., 2000). Hume et al. (1993) reported an improvement in the control of Salmonella in the intestinal tract by the concomitant use of organic acids and competitive exclusion products.

In the third experiment (Table 3), the association of both products also included a lower low dose of the acidifier $(1.5 \mathrm{~kg} / \mathrm{ton})$. Again, cecal colonization by Salmonella was prevented $(p<0.05)$. Similar results were obtained in the fourth experiment carried out also with both products together (Table 4), but at this time, the challenge was done by contact $(p<0.05)$.

\section{CONCLUSIONS}

Based on these results, we conclude that the welldefined multi-strain probiotic product $\left(\right.$ Biomin $^{\circledR}$ PoultryStar), offered via drinking water, controls the intestinal colonization of chickens by Salmonella Enteritidis. 


\section{REFERENCES}

Barcellos DESN, Borowski SM, Kuller FL, Prates ABH. Alternativas ao uso de antimicrobianos. A Hora Veterinária 2004; 140:53-54

Barrow PA, Huggis MB, Lovell MA, Simpson JM. Observations on the pathogenesis of experimental Salmonella Typhimurim infection in chickens. Research Veterinary Science 1987; 42:194-199.

Brasil. Ministério da Agricultura, Pecuária e Abastecimento. Programa nacional de sanidade avícola. Instrução Normativa 78, Diário Oficial da União, República Federativa do Brasil, Brasília-DF, 5 nov. 2003. Secretaria de Defesa Agropecuária, edição número 215 de 05/11/2003.

Cherrington CA, Hinton M, Mead GC, Chopra I. Organic acids: Chemistry, antibacterial activity and practical applications. Advances in Microbial Phisiology 1991; 32:87-108.

Gama NMSQ, Berchieri Jr A, Fernandes AS. Occurrence of Salmonella sp in laying hens. Brazilian Journal of Poultry Science 2003; 5(1):1521.

Hinton M, Linton AM. Control of Salmonella infections in broiler chickens by acid treatment of their feeds. The Veterinary Record 1988; 123:416-421.

Hinton M, Mead GC, Ympey CS. Protection of chicks against environmental challenge with Salmonella Enteritidis by competitive exclusion and acid-treated feed. Letters in Applied Microbiology $1991 ; 12: 69-71$

Hinton M, Mead GC. Salmonella control in poultry: the need for the satisfactory evolution of probiotics for this purpose. Letters in Applied Microbiology 1991; 13:49-50.

Hume ME, Corrier DE, Ivie GW, Deloach JR. Metabolism of $\left[{ }^{14} \mathrm{C}\right]$ propionic acid in broiler chicks. Poultry Science 1993; 72:786-793.

Iba AM, Berchieri Jr A. Studies on the use of a formic acid-propionic acid mixture (Bio-add ${ }^{\mathrm{TM}}$ ) to control experimental Salmonella infection in broiler chickens. Avian Pathology 1995; 24:303-311.
Luqueti BC, Torres KAA, Faria Filho DE, Figueiredo DF, Amaral CMC, Macari M. Efeito da vacinação contra coccidiose e da suplementação de parede celular de Saccharomyces cerevisiaesobre o desempenho de frango de corte. Brazilian Journal of Poultry Science 2005; Suppl: 228.

Mead GC. Prospects for "Competitive exclusion" treatment to control Salmonellas and other foodborne pathogens in poultry. The Veterinary Journa/2000; 159:111-123.

Nurmi E, Rantala M. New aspects of Salmonella infection in broiler production. Nature 1973; 241:210-211.

Oliveira GH, Berchieri Jr A, Barrow PA. Prevention of Salmonella infection by contact using intestinal flora of birds adult and/or a mixture of organic acids. Brazilian Journal of Microbiology 2000; $31: 116-120$

Santos Jr GL, Turnes CG. Probiotics in aviculture. Ciência Rural 2005; 35:741-747.

SAS Inst. SAS online doc version 9. Cary NC; 2002.

Schneitz C. Competitive exclusion in poultry -30 years of research. Food Control 2005; 16:657-667.

Vieira SL, Viola ES. Respostas fisiológicas de suínos a dietas com misturas de ácidos orgânicos. In: AviSui 2004 III Seminário Internacional de Aves e Suínos; 2004; Florianópolis, Santa Catarina, Brasil.

Wray C, Davies RH. Guidelines on detection and monitoring of Salmonella infected poultry flocks with particular reference of Salmonella Enteritidis. Graz (Austria): WHO, 1994. 17p.

Zancan FT, Berchieri Jr A, Fernandes SA. Salmonella spp investigation in transport boxes of day-old birds. Brazilian Journal of Microbiology 2000; 31(3):229-232.

Ziprin RL, Corrier DE, Deloach JR. Control of established Salmonella Typhimurium intestinal colonization with in vivo-passaged anaerobes. Avian Diseases 1993; 37:183-188. 